\title{
Clinical and economic efficiency to reduce dose etanercept and adalimumab in patients with rheumatoid arthritis
}

Rosalía Martínez-Pérez", Sergio Rodríguez-Montero, Alejandro Muñoz, Julia Uceda, Mario León, Francisco Gallo, Maria Luisa Velloso, José Luis Marenco

From 7th European Workshop on Immune-Mediated Inflammatory Diseases

Noordwijk aan Zee, the Netherlands. 28-30 November 2012

\section{Objective}

To assess the clinical and economic efficiency as well as functional capacity in patients with rheumatoid artritis treated with biologic after dose reduction.

\section{Methods}

A retrospective study on a cohort of 13 patients diagnosed rheumatoid artritis (RA) treated with anti-TNF (10 patients with etanercept, and 3 with adalimumab) and clinical remission (DAS28 < 2.6) in the last 6 months, in which reducing the dosing. This reduction was about $30 \%$ in both groups (etanercept passed from $25 \mathrm{mg}$ twice a week to $25 \mathrm{mg}$ every 5 days. In the case of Adalimumab it went from $40 \mathrm{mg}$ to $40 \mathrm{mg}$ every 2 weeks every 20 days.

Clinical activity was evaluated by clinical activity index (DAS28), for functional capacity was used HAQ (Health Assessment Questionnaire). Others variables studied was visual analog scale (VAS). Analyzing before starting dose reduction, at 3 and 6 months.

\section{Results}

The study includes 13 patients, 12 female, with RF in $90 \%$ and erosions in $40 \%$, treated with etanercept 10 and adalimumab 3. More of them (85\%) had recieved at least 2 FAMES before biological. Dose reduction in the etanercept group was 2 weekly injections to one injection every 5 days. In the case of adalimumab the pattern used was an injection every 20 days.

$60 \%$ (6/10) of patients with etanercept was maintained with a reduced schedule after 6 months, and 33\% $(1 / 3)$ of patients treated with adalimumab. During the study period was generated savings of EUR 17,768.90 for etanercept and adalimumab 5786.91 euros related to the dose reduction.

\section{Table 1}

\begin{tabular}{|c|c|c|c|c|}
\hline & BASELINE & 3 months ( $p$ baseline- $3 m$ ) & 6 months (p 3m-6m) & INFERENCE \\
\hline \multicolumn{5}{|c|}{ VAS $(\mathrm{mm})$} \\
\hline -ETN & $21.00 \pm 16.63$ & $26.50 \pm 18.56(p=0.048)$ & $23.89 \pm 17.28(p=0.22)$ & $p=0.89$ \\
\hline -ADA & $30.00 \pm 20.00$ & $38.67 \pm 18.03(p=0.49)$ & $20.00 \pm 19.36(p=0.54)$ & $p=0.36$ \\
\hline \multicolumn{5}{|l|}{$\mathrm{HAQ}$} \\
\hline -ETN & $0.48 \pm 0.50$ & $0.61 \pm 0.45(p=0.33)$ & $0.49 \pm 0.40(p=0.34)$ & $p=0.67$ \\
\hline$-A D A$ & $1.33 \pm 0.21$ & $1.66 \pm 0.28(p=0.19)$ & $1.93 \pm 0.26(p=0.25)$ & $p=0.003$ \\
\hline \multicolumn{5}{|c|}{ DAS28 } \\
\hline -ETN & $2.15 \pm 0.45$ & $2.74 \pm 0.85(p=0.056)$ & $2.41 \pm 0.77(p=0.005)$ & $p=0.20$ \\
\hline$-A D A$ & $2.13 \pm 0.47$ & $3.85 \pm 1.07(p=0.97)$ & $2.98 \pm 1.03(p=0.005)$ & $p=0.005$ \\
\hline
\end{tabular}

Rheumatology Unit, Valme University Hospital, Sevilla, Spain

๑ 2012 Martínez-Pérez et al; licensee BioMed Central Ltd. This is an Open Access article distributed under the terms of the Creative 


\section{Conclusions}

The reduction of etanercept and adalimumab doses in patients with rheumatoid arthritis in clinical remission (DAS28 < 2.6), It seems to be an effective strategy given that in the patients in this study were able to maintain the good clinical (DAS 28 and VAS) in 60\% of patients treated with etanercept and $33 \%$ with adalimumab. Not so the HAQ in which if there are significant differences that support that after the patient expresses reduce doses higher score on the test. Although the results 6 of 13 patients (46.2\%) return to your regular schedule by mutual selfreferred as subjectively feel worse and increase in seizures of exacerbation.

In the light of the results of this study the dosage reduction can be an efficient alternative at the time of treating patients with RA into remission.

Published: 28 November 2012

doi:10.1186/1479-5876-10-S3-P51

Cite this article as: Martínez-Pérez et al:: Clinical and economic efficiency to reduce dose etanercept and adalimumab in patients with rheumatoid arthritis. Journal of Translational Medicine 2012 10(Suppl 3): P51.

Submit your next manuscript to BioMed Central and take full advantage of:

- Convenient online submission

- Thorough peer review

- No space constraints or color figure charges

- Immediate publication on acceptance

- Inclusion in PubMed, CAS, Scopus and Google Scholar

- Research which is freely available for redistribution 